\title{
The synthesis of Co-doped SAPO-5 molecular sieve and its performance in the oxidation of cyclohexane with molecular oxygen
}

\author{
Zhun Xiao, Wangcheng Zhan *, Yun Guo, Yanglong Guo, Xueqing Gong, Guanzhong Lu \# \\ Key Laboratory for Advanced Materials and Research Institute of Industrial Catalysis, East China University of Science and Technology, Shanghai 200237, \\ China
}

A R T I C L E I N F O

Article history:

Received 25 August 2015

Accepted 10 November 2015

Published 5 February 2016

\section{Keywords:}

SAPO-5 molecular sieve

Cobalt

Cyclohexane

Selective oxidation

Oxygen

\begin{abstract}
A B S T R A C T
Silicoaluminophosphate (SAPO) molecular sieves doped with cobalt (Co-SAPO-5) were synthesized hydrothermally with different concentrations of Co. Each sample was characterized by X-ray diffraction, $\mathrm{N}_{2}$ adsorption-desorption, scanning electron microscopy, ultraviolet-visible spectroscopy, temperature-programmed desorption of $\mathrm{NH}_{3}\left(\mathrm{NH}_{3}-\mathrm{TPD}\right)$, and infrared spectrascopy of adsorbed pyridine (Py-IR). The results showed that Co was highly dispersed in the Co-SAPO-5 samples. In addition, a part of the Co content had been incorporated into the SAPO- 5 framework, while the remainder existed on the surface as extra-framework Co. The surface areas of the Co-SAOP-5 samples were similar to the SAPO- 5 sample. However, the pore volumes of the Co-SAOP- 5 samples were lower than that of the SAOP-5 sample. As the concentration of Co increased, the pore volume gradually decreased because extra-framework cobalt oxide was present on the catalyst surface. $\mathrm{NH}_{3}$-TPD and Py-IR results revealed that the amount of Brønsted acid and the total amount of acid for the Co-SAPO-5 samples were higher than that for the SAPO-5 sample. These values were also higher for samples with higher Co content. The catalytic activity of the Co-SAPO-5 samples was evaluated for the oxidation of cyclohexane with molecular oxygen. When Co was added to the SAPO- 5 catalyst, the catalytic activity of the Co-SAPO- 5 catalysts improved. In addition, the conversion of cyclohexane increased as the Co content in the Co-SAPO-5 catalysts increased. However, with a high conversion of cyclohexane $(>6.30 \%)$, the total selectivity of cyclohexanone $(\mathrm{K})$ and cyclohexanol $(\mathrm{A})$ decreased sharply. The K/A ratio ranged from 1.15 to 2.47 . The effects of reaction conditions (i.e., reaction temperature, reaction time, initial oxygen pressure, and the catalyst amount) on the performance of the Co-SAPO- 5 catalysts have also been measured. Furthermore, the stability of the Co-SAPO-5 catalyst was explored and found to be good for the selective oxidation of cyclohexane by molecular oxygen.
\end{abstract}

(C) 2016, Dalian Institute of Chemical Physics, Chinese Academy of Sciences. Published by Elsevier B.V. All rights reserved.

\section{Introduction}

Cyclohexanone and cyclohexanol (KA) are important intermediates in the production of adipic acid and caprolactam, which are used in the manufacture of nylon- 6 and nylon-66 polymers, respectively [1,2]. In addition, they are used as solvents for shellacs, lacquers and varnishes, stabilizers and homogenizers for soaps and synthetic detergent emulsions, and

\footnotetext{
*Corresponding author. Tel/Fax: +86-21-64252923; E-mail: zhanwc@ecust.edu.cn

\# Corresponding author. Fax: +86-21-64252827; E-mail: gzhlu@ecust.edu.cn

This work was supported by the National Basic Research Program of China (2010CB732300) and the National Natural Science Foundation of China (21103048).
}

DOI: 10.1016/S1872-2067(15)61014-2 | http://www.sciencedirect.com/science/journal/18722067 | Chin. J. Catal., Vol. 37, No. 2, February 2016 
as the starting material in the synthesis of insecticides, herbicides, and pharmaceuticals [3]. The oxidation of cyclohexane is an important industrial process to produce cyclohexanone and cyclohexanol; however, the productivity of this process is very low by now [4]. Currently, the most important catalyst system in use for industrial cyclohexane oxidation employs homogeneous Co salts [5]. To prevent the over-oxidation of cyclohexane, conversion is generally kept below $5 \%$ and the total selectivity of cyclohexanone and cyclohexanol reaches $70 \%-80 \%$ [6].

The oxidation of cyclohexane with $\mathrm{O}_{2}$ follows the radical chain mechanism [7]. Transition-metal ions, such as $\mathrm{Co}^{2+}, \mathrm{Cr}^{3+}$, $\mathrm{Mn}^{2+}$, and $\mathrm{Ce}^{2+}$, accelerate free radical chain reactions. Consequently, heterogeneous catalysts that contain these ions have been extensively used to catalyze cyclohexane oxidation [8]. On the other hand, molecular sieves based on aluminophosphates have been synthesized and exhibit a huge potential for catalytic applications because of their unique pore structure and low acidity $[9,10]$. However, doping heteroatoms into the aluminophosphate framework tends to break the charge balance and leads to an improvement in acidity [11-13]. Therefore, because of their mild acidity and shape selectivity, silicoaluminophosphate (SAPO) molecular sieves (such as SAPO-5) have been used as solid acid catalysts for some hydrocarbon reactions. Some of these reactions include the dehydration of ethanol [14], the hydroisomerization of 1-octene [15], the conversion of methanol to olefin [16], the dimerization of propene [17], and the epoxidation of styrene [18]. The enhanced selectivities and decreased deactivation rates were observed for both medium pore-sized SAPO and metalloaluminophosphate molecular sieves.

The main objective of this work was to heterogenize the conventional homogeneous Co salt catalysts by loading them onto a SAPO support. This work also evaluates how the activity for cyclohexane oxidation with $\mathrm{O}_{2}$ was affected by the doping of SAPO-5 samples with Co. It is worth looking ahead to provide an efficient catalyst for the oxidation of cyclohexane with $\mathrm{O}_{2}$.

\section{Experimental}

\subsection{Synthesis of Co-SAPO-5 materials}

The Co-doped SAPO-5 molecular sieves were synthesized by the hydrothermal method. The following chemicals were used: triethylamine (TEA) as the template, tetraethyl orthosilicate (TEOS) as the silica source, aluminum isopropoxide as the $\mathrm{Al}$ source, and $\mathrm{H}_{3} \mathrm{PO}_{4}$ as the phosphorus source. In a typical synthesis, a fixed amount of $\mathrm{Co}\left(\mathrm{NO}_{3}\right)_{3} \cdot 6 \mathrm{H}_{2} \mathrm{O}$ solution was initially mixed with $5.76 \mathrm{~g}$ of phosphoric acid and $18 \mathrm{~mL}$ of deionized water. Next, $10.21 \mathrm{~g}$ of aluminum isopropoxide was added to the mixture and stirred at room temperature until completely dissolved. Then, $3.13 \mathrm{~g}$ of the TEOS was added dropwise to the solution and continuously stirring for $1 \mathrm{~h}$. Finally, $3.5 \mathrm{~mL}$ of the TEA template was added and stirred for an additional $3 \mathrm{~h}$. The initial gel formed was transferred to a Teflon-lined stainless steel autoclave and heated to $180{ }^{\circ} \mathrm{C}$ for $24 \mathrm{~h}$. After crystallization, the product was filtered, washed with deionized water, dried at $100{ }^{\circ} \mathrm{C}$ for $24 \mathrm{~h}$, and calcined in air at $550{ }^{\circ} \mathrm{C}$ for $5 \mathrm{~h}$ to remove the template. The synthesized samples were recorded as Co-SAPO-5- $x$, where $x$ represents the different Co/Si molar ratios in the initial gels.

The SAPO-5 molecular sieve was also prepared with the same procedure, except that no $\mathrm{Co}\left(\mathrm{NO}_{3}\right)_{3} \cdot 6 \mathrm{H}_{2} \mathrm{O}$ was added.

\subsection{Characterization of samples}

Powder X-ray diffraction (XRD) patterns were recorded on a Bruker D8 diffractometer using $\mathrm{Cu} K_{\alpha}$ radiation $(\lambda=0.154056$ $\mathrm{nm}$ ) operating at $40 \mathrm{kV}$ and $40 \mathrm{~mA}$. The morphologies of the catalysts were analyzed with scanning electron microscopy (SEM) using a Hitachi S-3400N operated with a beam energy of $15 \mathrm{kV}$. The elemental compositions of the samples were analyzed with ICP (TJA IRIS ADVANTAGE 1000) and EDS (EDAX Falion). The Varian Cary 500 UV-Vis-NIR spectrophotometer was used to record the ultraviolet-visible (UV-vis) spectra in the range of $200-800 \mathrm{~nm}$, with $\mathrm{BaSO}_{4}$ as the reference. Infrared spectra of adsorbed pyridine (Py-IR) of the samples were analyzed using a Nicolet Nexus 670 FT-IR spectrometer.

$\mathrm{NH}_{3}$-TPD was carried out in an in-house manufactured equipment. The sample was initially pretreated at $600{ }^{\circ} \mathrm{C}$ for 30 min and cooled to room temperature under $\mathrm{N}_{2}$. It was then exposed to the $10 \% \mathrm{NH}_{3} / \mathrm{N}_{2}$ mixture gas and allowed to adsorb $\mathrm{NH}_{3}$ for $1 \mathrm{~h}$. After this adsorption time, the sample was purged at room temperature for $1.5 \mathrm{~h}$ under $\mathrm{N}_{2}$. Finally, the sample was heated at a rate of $10^{\circ} \mathrm{C} / \mathrm{min}$ to $600^{\circ} \mathrm{C}$.

\subsection{Catalytic activity testing}

The catalytic activities of the SAPO-5 and Co-SAPO-5 catalysts were investigated for the selective oxidation of cyclohexane with $\mathrm{O}_{2}$ as the oxidant. No solvents were added during the process. In the typical reaction, $4 \mathrm{~g}$ of cyclohexane and $20 \mathrm{mg}$ of catalyst were introduced into the reactor. After $\mathrm{O}_{2}$ was charged to $0.5 \mathrm{MPa}$, the reactor was heated to $140{ }^{\circ} \mathrm{C}$. The samples were stirred continuously and kept at $140{ }^{\circ} \mathrm{C}$ for $4 \mathrm{~h}$. After the reaction was completed, the catalyst was separated by centrifugation. The reaction products were analyzed using a flame ionization detector and the Agilent 7890B gas chromatograph, which was equipped with an HP-5 capillary column. Methylbenzene was used as the internal standard.

Recycling tests were carried out on the regenerated Co-SAPO-5-0.2 catalyst. After the reaction was completed, the catalyst was separated from the reaction solution by filtration, washed three times with ethyl alcohol in a glass beaker (while stirring), dried at $100{ }^{\circ} \mathrm{C}$ for $6 \mathrm{~h}$, and then calcined in air at 550 ${ }^{\circ} \mathrm{C}$ for $2 \mathrm{~h}$. The regenerated catalyst was supplemented with fresh catalyst and its catalytic performance was tested and compared with the fresh catalyst.

\section{Results and discussion}

\subsection{Characterization of catalysts}

The powder XRD patterns of the synthesized Co-SAPO-5- $X$ 


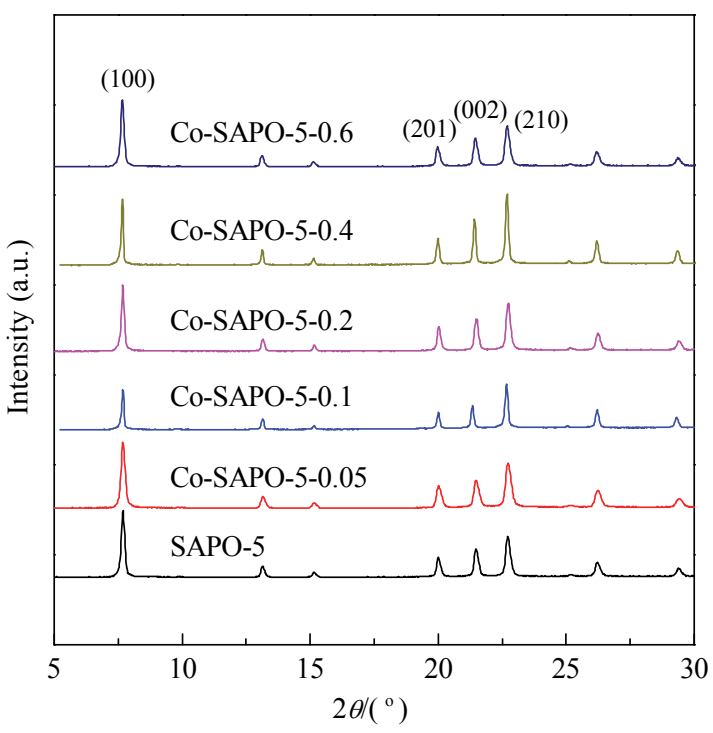

Fig. 1. XRD patterns of the Co-SAPO-5- $x$ samples.

samples are shown in Fig. 1. The most intense diffraction peak of SAPO-5 (100) appeared at $2 \theta=7.4^{\circ}$. The higher order intense diffraction peaks appeared at $2 \theta=19^{\circ}-23^{\circ}$. These peaks agreed well with those of the SAPO-5 [19]. After the addition of Co, the XRD patterns of the Co-SAPO-5- $x$ samples were similar to that of the SAPO-5 sample. The XRD patterns of the Co-SAPO-5- $x$ samples did not show any cobalt oxide diffraction peaks. However, metallic Co was detected on the Co-SAPO-5- $X$ samples and is shown in Table 1 . These results indicate that Co was highly dispersed on the Co-SAPO-5- $x$ samples, even with a Co metal content of $0.64 \mathrm{wt} \%$.

Table 1 shows the BET surface area and pore volume for each sample. These results indicate that the surface areas of the Co-SAOP-5 samples were similar to that of SAPO-5. In contrast, the pore volumes of the Co-SAOP-5 samples were lower than that of SAOP-5, and gradually decreased as the Co content increased. There were no diffraction peaks of cobalt oxide in the XRD patterns for the Co-SAPO-5- $x$ samples. Metallic Co was highly dispersed over the Co-SAPO-5- $x$ samples. The presence of extra-framework cobalt oxide on the surface was detected by UV-vis spectroscopy, which may result in a decrease in pore volume of the Co-SAOP-5 samples when increasing Co content.

Figure 2 shows SEM images of the synthesized SAPO- 5 and Co-SAP0-5-0.2 samples. The SAPO-5 sample exhibited columnar joint morphology. After Co addition, the morphology of the

Table 1

Structural and textural parameters of the Co-SAPO-5- $x$ samples.

\begin{tabular}{|c|c|c|c|c|}
\hline \multirow{2}{*}{ Sample } & \multicolumn{2}{|c|}{ Co content (wt\%) } & \multirow{2}{*}{$\begin{array}{c}\text { Surface area } \\
\left(\mathrm{m}^{2} / \mathrm{g}\right)\end{array}$} & \multirow{2}{*}{$\begin{array}{l}\text { Pore volume } \\
\left(\mathrm{cm}^{3} / \mathrm{g}\right)\end{array}$} \\
\hline & Theoretical & Actual $^{a}$ & & \\
\hline$\overline{\text { SAPO-5 }}$ & - & - & 242.4 & 0.365 \\
\hline Co-SAOP-5-0.05 & 0.05 & 0.05 & 236.8 & 0.279 \\
\hline Co-SAOP-5-0.1 & 0.1 & 0.12 & 263.0 & 0.207 \\
\hline Co-SAOP-5-0.2 & 0.2 & 0.21 & 238.8 & 0.191 \\
\hline Co-SAOP-5-0.4 & 0.4 & 0.48 & 245.2 & 0.192 \\
\hline Co-SAOP-5-0.6 & 0.6 & 0.64 & 244.9 & 0.180 \\
\hline
\end{tabular}

a Determined by ICP-AES.

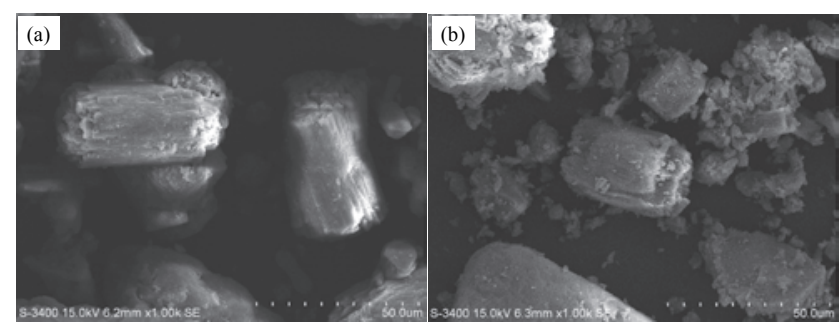

Fig. 2. SEM images of SAPO-5 (a) and the Co-SAPO-5-0.2 sample (b).

Co-SAPO-5-0.2 sample became disorderly and was composed of bulk and column particles of random sizes.

UV-vis spectroscopy was used to characterize the nature and coordination number of the cobalt oxide species in the Co-SAP-5- $x$ samples. The results are shown in Fig. 3. In the case of SAPO-5, there were no adsorption peaks in the wavelength range of 250-800 $\mathrm{nm}$. However, three major groups of absorption peaks appeared at 320,410 , and $525-650 \mathrm{~nm}$ for all the Co-SAPO-5- $x$ samples. The absorption peaks at 320 and $410 \mathrm{~nm}$ are attributed to the mixed oxide of cobalt outside the framework. The group of absorption peaks at 537, 580, and $630 \mathrm{~nm}$ is attributed to the tetrahedrally coordinated $\mathrm{Co}^{2+}$ in the framework [20-23]. These results suggest that part of the cobalt had been incorporated into the SAPO-5 framework, while the remaining amount existed as the extra-framework cobalt on the surface. Furthermore, the intensities of these absorption peaks increased as the Co content of the Co-SAPO-5- $x$ samples increased. This indicates that the amount of cobalt, in both the framework and extra-framework, increased with increasing Co content in the Co-SAPO-5- $x$ samples.

Figure 4 shows the $\mathrm{NH}_{3}$-TPD curves of the Co-SAPO-5- $x$ samples. The results indicate that there are two $\mathrm{NH}_{3}$ desorption peaks for all samples, which can be ascribed to the weak acid $\left(181{ }^{\circ} \mathrm{C}\right)$ and the medium strong acid $\left(285^{\circ} \mathrm{C}\right)$, respectively [24]. It is noted that the intensities of the desorption peaks at $285{ }^{\circ} \mathrm{C}$ increased with increasing Co content. In contrast, the intensities of the desorption peaks at $181{ }^{\circ} \mathrm{C}$ hardly changed. As a result, the total acid content increased as the Co content in the Co-SAP0-5- $x$ samples increased.

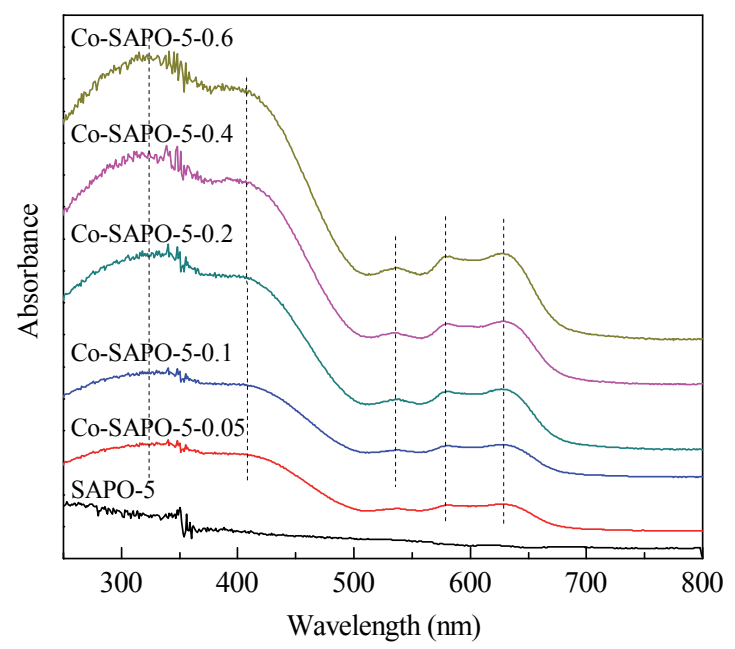

Fig. 3. UV-vis spectra of the Co-SAPO-5- $x$ samples. 


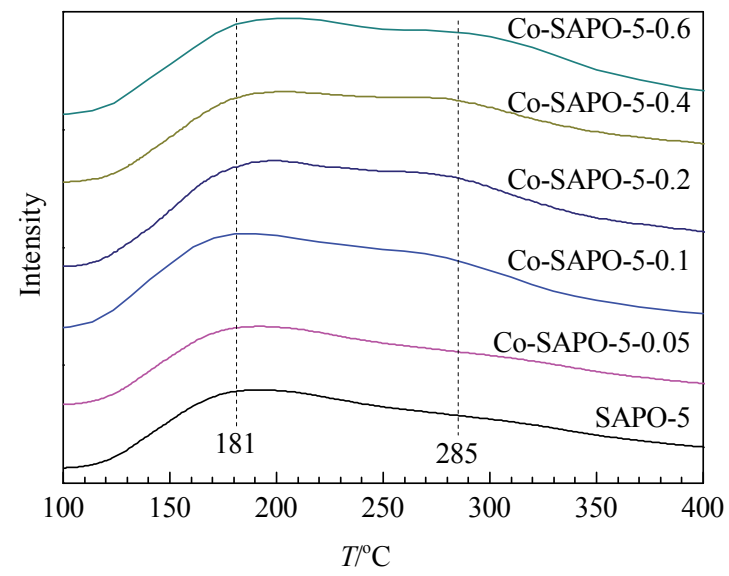

Fig. 4. $\mathrm{NH}_{3}-\mathrm{TPD}$ curves of the Co-SAPO-5- $x$ samples.

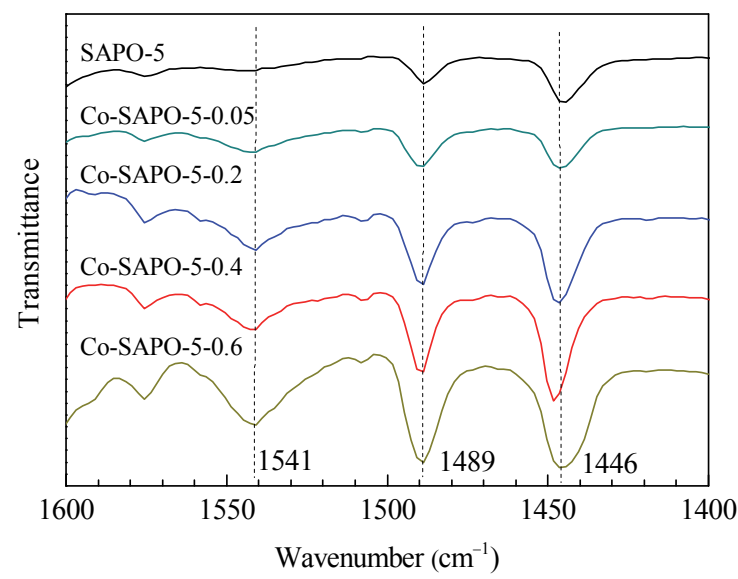

Fig. 5. Py-IR spectra of the Co-SAPO-5- $x$ samples.

The Py-IR spectra of the Co-SAPO-5- $x$ samples were recorded between 1400 and $1600 \mathrm{~cm}^{-1}$ and are shown in Fig. 5. Three main absorption peaks were seen at 1446, 1489, and $1541 \mathrm{~cm}^{-1}$. The absorption peaks at 1446 and $1541 \mathrm{~cm}^{-1}$ were assigned to the Lewis acid and Brønsted acid, respectively. The absorption peaks at $1489 \mathrm{~cm}^{-1}$ was assigned to both acids. The amount of acid for the samples was calculated and is shown in Table 2. The results show that the amount of Brønsted acid in the Co-SAPO-5- $x$ samples is higher than that in the SAPO-5 sample. In addition, the amount increased with increasing Co content. However, the amount of Lewis acid did not change significantly. The total amount of acid on the surface of the Co-SAPO-5- $x$ samples increased with Co addition because of the increased Co content. This is consistent with $\mathrm{NH}_{3}$-TPD results.
Table 3

The catalytic activities of the Co-SAPO-5- $x$ catalysts for cyclohexane oxidation.

\begin{tabular}{|c|c|c|c|c|c|}
\hline \multirow[b]{2}{*}{ Catalyst } & \multirow{2}{*}{$\begin{array}{c}\text { Conver- } \\
\text { sion } \\
(\%)\end{array}$} & \multicolumn{3}{|c|}{ Selectivity (\%) } & \multirow{2}{*}{$\begin{array}{l}\mathrm{K} / \mathrm{A} \\
\text { ratio }\end{array}$} \\
\hline & & $\begin{array}{c}\text { Cyclohexa- } \\
\text { nol (A) }\end{array}$ & $\begin{array}{c}\text { Cyclohexa- } \\
\text { none (K) }\end{array}$ & KA oil & \\
\hline SAOP-5 & 4.45 & 32.14 & 51.15 & 9 & 1.59 \\
\hline Co-SAOP-5-0.05 & 5.22 & 44.00 & 50.78 & 94.78 & 1.15 \\
\hline Co-SAOP-5-0.1 & 6.30 & 40.03 & 56.96 & 96.99 & 1.42 \\
\hline Co-SAOP-5-0.2 & 10.37 & 27.29 & 47.92 & 75.21 & 1.76 \\
\hline Co-SAOP-5-0.4 & 12.36 & 14.18 & 35.06 & 49.24 & 2.47 \\
\hline Co-SAOP-5-0.6 & 19.17 & 9.27 & 18.00 & 27.27 & 1.94 \\
\hline
\end{tabular}

Reaction conditions: cyclohexane $4 \mathrm{~g}$, catalyst $20 \mathrm{mg}$, initial $p\left(\mathrm{O}_{2}\right)=1.0$ $\mathrm{MPa}, 140^{\circ} \mathrm{C}, 4 \mathrm{~h}$.

In other words, the introduction of Co in the SAPO-5 sample obviously increased the total amount of acid on the surface of the Co-SAPO-5- $x$ samples.

\subsection{Catalytic activity for cyclohexane oxidation}

This section evaluates the catalytic performance of the Co-SAPO-5- $x$ samples, where cyclohexane is oxidized by molecular oxygen. As shown in Table 3, the SAPO-5 catalyst achieved a $4.45 \%$ cyclohexane conversion, with an $83.29 \%$ selectivity towards KA oil. When Co was added to the SAPO-5 catalyst, the catalytic activity of the Co-SAPO-5- $x$ catalysts improved. An increase in the Co content of the Co-SAPO-5- $x$ catalysts resulted in an increase in the conversion of cyclohexane. The oxidation of cyclohexane with $\mathrm{O}_{2}$ is known to proceed via the complex radical-chain mechanism [7,25-27]. The chain initiation proceeds through the homolytic cleavage of cyclohexyl hydroperoxide ( $\mathrm{CyOOH}$ ) according to the reaction $\mathrm{CyOOH}$ $\rightarrow \mathrm{CyO}+\cdot \mathrm{OH}$. The $\mathrm{Co}^{2+}$ ion catalyzes this initiation via the Haber-Weiss cycle $[28,29]$, which leads to an increase in the cyclohexane conversion over the Co-SAPO-5- $x$ catalysts. In addition, the selectivity towards both cyclohexanol and cyclohexanone initially increased, and then decreased violently due to an over-oxidation of the relatively reactive oxygenates. There are two commercial processes: the non-catalytic autoxidation process, and the catalyzed oxidation that uses Co-based homogeneous catalysts. The K/A ratios are generally 1.5 and $0.3-0.5$, respectively $[30,31]$. In the present study, the $\mathrm{K} / \mathrm{A}$ ratio ranged from 1.15 to 2.47 , which indicates that the Co-SAPO-5- $x$ catalyst is real and not simply a promoter of the autoxidation pathways for cyclohexane oxidation. Furthermore, the catalytic role of the Co-SAPO-5- $x$ catalyst during cyclohexane oxidation is different from the Co-based homogeneous catalysts.

Table 2

Acid properties of the Co-SAPO-5-x samples as calculated by Py-IR spectra.

\begin{tabular}{|c|c|c|c|c|c|c|}
\hline \multirow{2}{*}{ Sample } & \multirow{2}{*}{$m / g$} & \multicolumn{2}{|c|}{ Area of absorption peak } & \multicolumn{3}{|c|}{ Amount of acid $(\mu \mathrm{mol} / \mathrm{g})$} \\
\hline & & Assigned to Brønsted acid & Assigned to Lewis acid & Brønsted acid & Lewis acid & Total acid \\
\hline$\overline{\text { SAPO-5 }}$ & 0.0422 & 0.29 & 7.77 & 5.4 & 110.4 & 115.8 \\
\hline Co-SAPO-5-0.05 & 0.0396 & 1.30 & 6.56 & 26.1 & 99.5 & 125.6 \\
\hline Co-SAPO-5-0.2 & 0.0470 & 3.57 & 5.62 & 60.4 & 71.7 & 132.1 \\
\hline Co-SAPO-5-0.4 & 0.0461 & 4.62 & 5.75 & 79.6 & 74.8 & 154.4 \\
\hline Co-SAPO-5-0.5 & 0.0433 & 5.19 & 7.15 & 95.2 & 99.1 & 194.3 \\
\hline
\end{tabular}




\subsection{Effects of reaction conditions on the catalytic activity}

The effect of reaction temperature on the catalytic activity of the Co-SAPO-5-0.1 and Co-SAP0-5-0.2 samples are shown in Fig. 6. The results show that the conversion of cyclohexane increases as temperature increases from 100 to $140{ }^{\circ} \mathrm{C}$. The selectivity towards both cyclohexanol and cyclohexanone increased to $140{ }^{\circ} \mathrm{C}$ before dropping rapidly because of deep oxidation of the products. Both Co-SAPO-5- $x$ catalysts exhibited the highest yield of cyclohexanol and cyclohexanone at $140{ }^{\circ} \mathrm{C}$.

Figure 7 shows the influence of reaction time on the catalytic activity of the Co-SAP0-5-0.1 and Co-SAPO-5-0.2 catalysts for the oxidation of cyclohexane. As the reaction time for both catalysts increased, the conversion of cyclohexane gradually increased. In contrast, the selectivity towards cyclohexanol clearly decreased. In addition, the selectivity towards cyclohexanone increased initially and then significantly decreased over both catalysts. However, the reaction time with the maximum selectivity towards cyclohexanone is different for both catalysts because the reaction rates are based on the different Co contents of the catalysts. Taking the yield of KA oil into account, Co-SAPO-5-0.1 and Co-SAPO-5-0.2 exhibited the best reactivity over the reaction time of 6 and $4 \mathrm{~h}$, respectively.

Figure 8 shows the influence of the initial oxygen pressure on the catalytic activity of the Co-SAPO-5-0.1 and Co-SAPO-5-0.2 catalysts for cyclohexane oxidation. As the initial oxygen pressure increased, the conversion of cyclohexane gradually increased over both catalysts, but the selectivity towards cyclohexanone decreased. The selectivity towards cyclohexanol showed a different trend over both catalysts. In the case of Co-SAPO-5-0.1, selectivity initially increased and then decreased suddenly. In contrast, in the case of Co-SAPO-5-0.2, selectivity consistently decreased. At the initial oxygen pressure of $1.0 \mathrm{MPa}$, the yield of KA oil reached $6.1 \%$ and $7.8 \%$ over Co-SAPO-5-0.1 and Co-SAPO-5-0.2, respectively.

Figure 9 shows the influence of catalyst amount on the catalytic activities of both Co-SAPO-5-0.1 and Co-SAPO-5-0.2 catalysts for the oxidation of cyclohexane. As the amount of both catalysts increased from $10 \mathrm{mg}$ to $30 \mathrm{mg}$, the conversion of cyclohexane increased gradually, and the selectivity towards cyclohexanone decreased gradually. However, the selectivity towards cyclohexanol showed different changing trends over both catalysts: for Co-SAPO-5-0.1, selectivity initially increased and then decreased; in the case of Co-SAPO-5-0.2, selectivity consistently decreased. Consequently, the highest yield of KA oil for the Co-SAPO-5-0.1 and Co-SAPO-5-0.2 catalysts reached $6.9 \%$ (with $30 \mathrm{mg}$ ) and $7.8 \%$ (with $20 \mathrm{mg}$ ), respectively.

\subsection{Stability test}

Based on its high activities for the oxidation of cyclohexane, the reusability of the Co-SAPO-5-0.2 catalyst was examined and the results are shown in Fig. 10. After the Co-SAPO-5-0.2 catalyst was reused six times, no obvious losses in activity or selec-
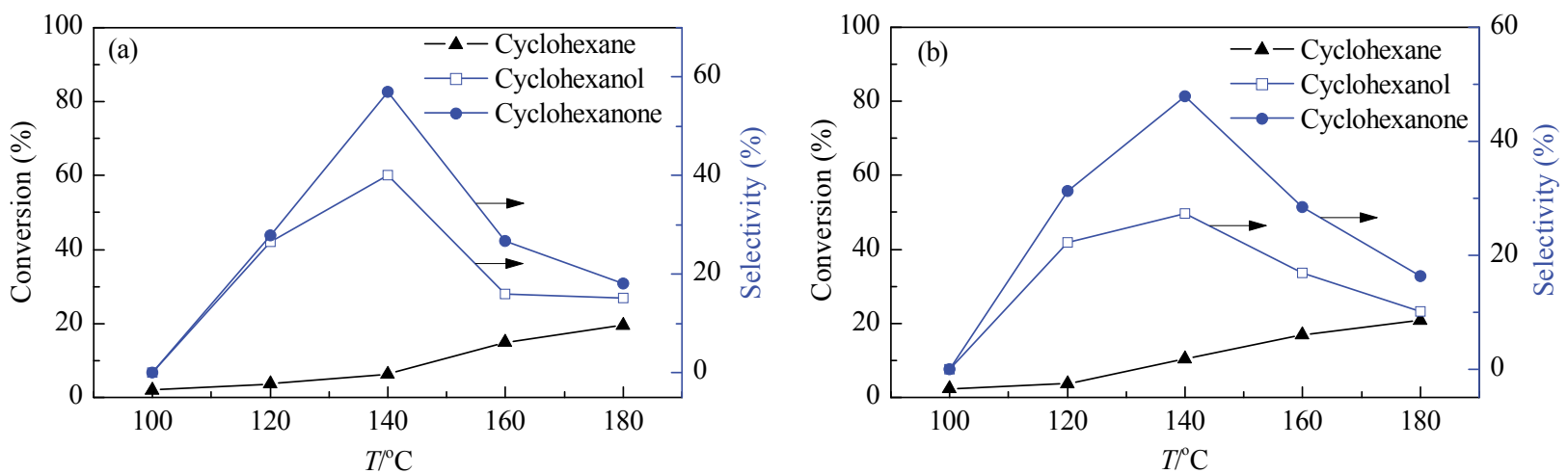

Fig. 6. The influence of reaction temperature on the catalytic activities of Co-SAPO-5-0.1 (a) and Co-SAPO-5-0.2 (b) catalysts for the oxidation of cyclohexane. Reaction conditions: catalyst $20 \mathrm{mg}$, cyclohexane $4 \mathrm{~g}$, initial $p\left(\mathrm{O}_{2}\right)=1.0 \mathrm{MPa}, 4 \mathrm{~h}$.
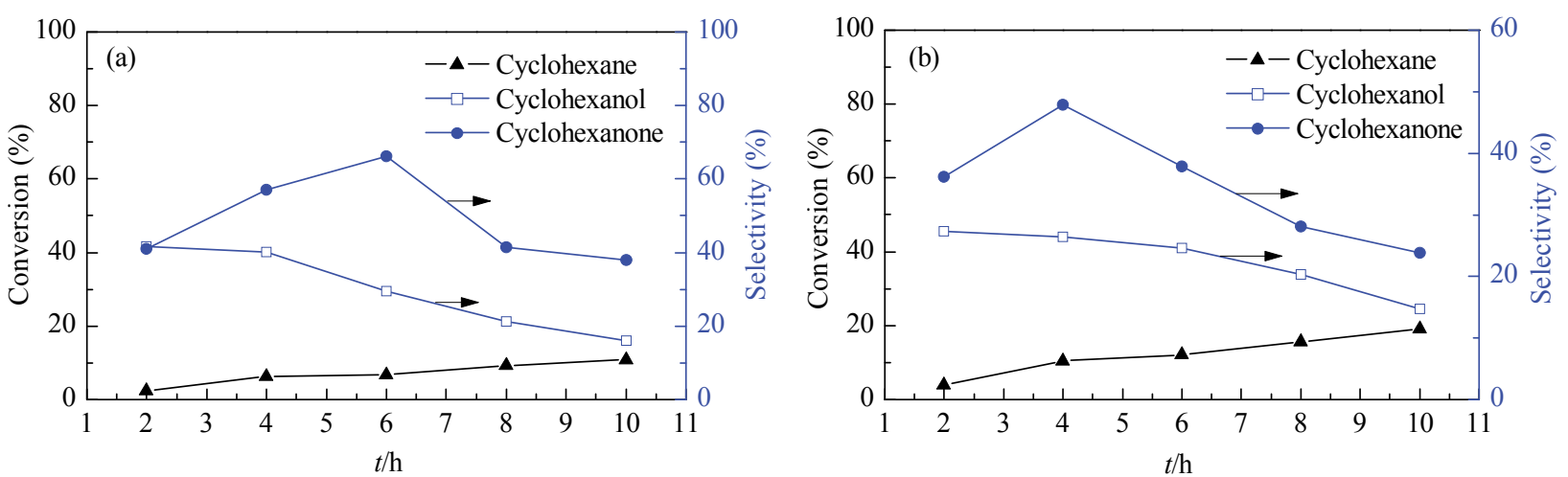

Fig. 7. The influence of reaction time on the catalytic activities of Co-SAPO-5-0.1 (a) and Co-SAPO-5-0.2 (b) catalysts for the oxidation of cyclohexane. Reaction conditions: catalyst $20 \mathrm{mg}$, cyclohexane $4 \mathrm{~g}$, initial $p\left(\mathrm{O}_{2}\right)=1.0 \mathrm{MPa}, 140^{\circ} \mathrm{C}$. 

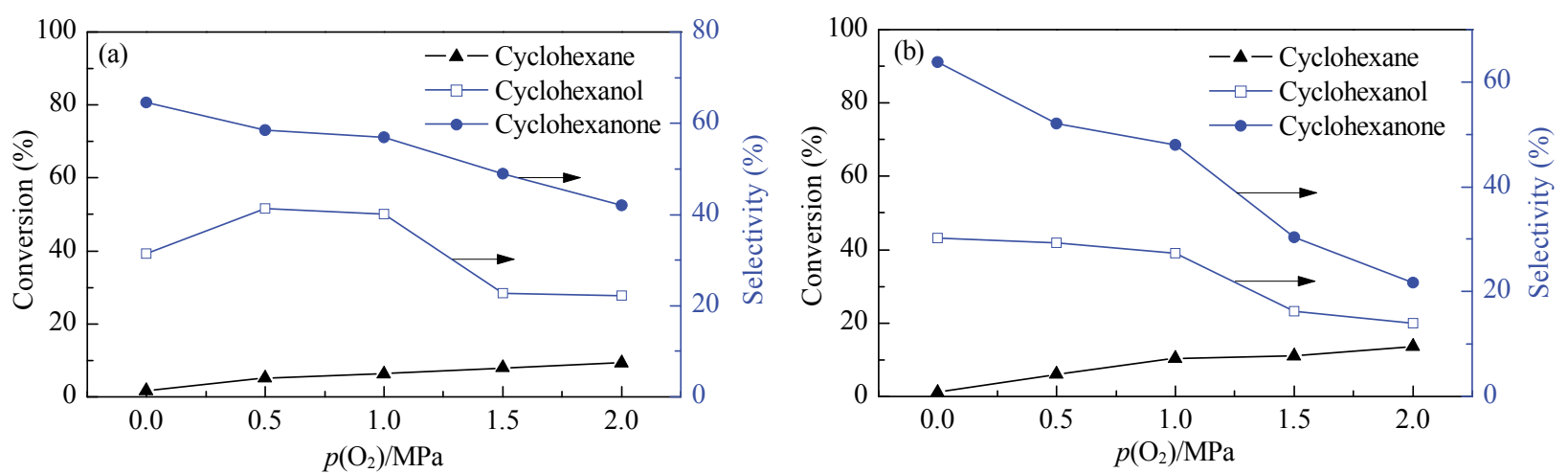

Fig. 8. The influence of initial oxygen pressure on the catalytic activities of Co-SAPO-5-0.1 (a) and Co-SAPO-5-0.2 (b) catalysts for the oxidation of cyclohexane. Reaction conditions: catalyst $20 \mathrm{mg}$, cyclohexane $4 \mathrm{~g}, 140^{\circ} \mathrm{C}, 4 \mathrm{~h}$.
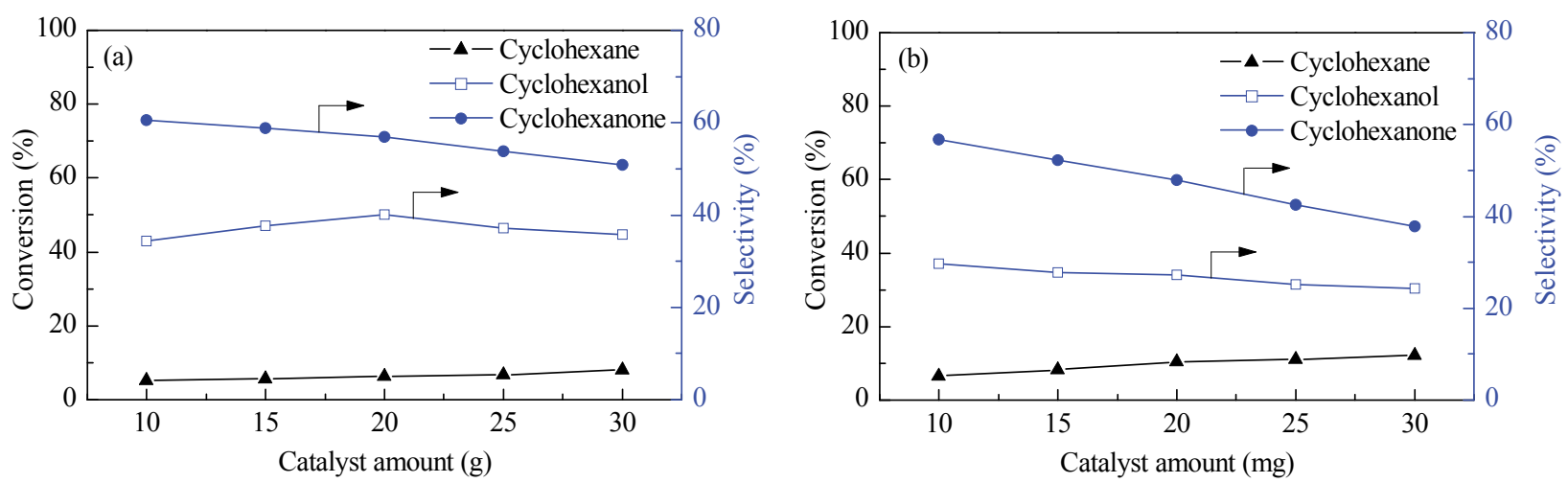

Fig. 9. The influence of the catalyst amount on the catalytic activities of Co-SAPO-5-0.1 (a) and Co-SAPO-5-0.2 (b) catalysts for the oxidation of cyclohexane. Reaction conditions: cyclohexane $4 \mathrm{~g}$, initial $p\left(\mathrm{O}_{2}\right)=1.0 \mathrm{MPa}, 140^{\circ} \mathrm{C}, 4 \mathrm{~h}$.

tivity were observed, thereby showing an excellent stability of the catalyst.

\section{Conclusions}

Co-SAPO-5- $x$ molecular sieves with different Co contents were synthesized using the hydrothermal method. A portion of the cobalt was incorporated into the SAPO-5 framework. The remaining amount existed as extra-framework cobalt on the surface, thereby leading to a decrease in the pore volume of the

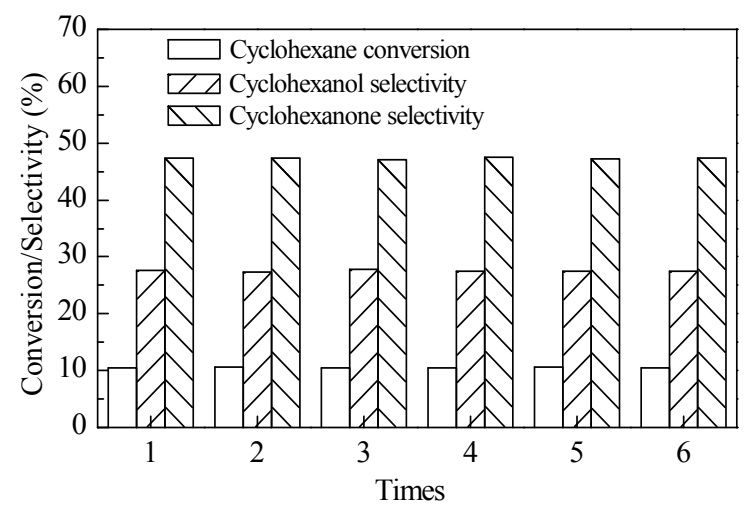

Fig. 10. Reusability of the Co-SAPO-5-0.2 catalyst for cyclohexane oxidation. Reaction conditions: catalyst $20 \mathrm{mg}$, cyclohexane $4 \mathrm{~g}$, initial $p\left(\mathrm{O}_{2}\right)=1.0 \mathrm{MPa}, 140^{\circ} \mathrm{C}, 4 \mathrm{~h}$.
Co-SAOP-5- $x$ samples. In addition, the amount of Brønsted acid and the total amount of acid for the Co-SAPO-5 samples were higher with an increase in the Co content. The activity test of the Co-SAPO-5 samples (for the oxidation of cyclohexane with $\mathrm{O}_{2}$ ) showed that the conversion of cyclohexane increased with an increase in the Co content. However, the selectivity of KA oil decreased rapidly when the conversion of cyclohexane was higher than $6.3 \%$ and when the K/A ratio ranged from 1.15 to 2.47. The Co-SAPO-5- $x$ catalyst was determined to be a real catalyst and not a promoter of the autoxidation pathways for cyclohexane oxidation. Its catalytic role in cyclohexane oxidation is different from the Co-based homogeneous catalysts. The reaction temperature, reaction time, initial oxygen pressure, and catalyst amount influenced the catalytic activities of the Co-SAPO-5- $x$ catalysts. In addition, the Co-SAPO-5-0.2 catalyst possesses excellent stability because its activity remained mostly unchanged after being used repeatedly six times.

\section{References}

[1] J. G. Speight, Chemical and Process Design Handbook., McGraw-Hill, New York, 2002, 2,185.

[2] D. D. Davis. In: W. Gerhartz, Y. S. Yamamoto, F. T. Campbell, R. Pfefferkorn, J. F. Rounsaville eds. Ullmann's Encyclopedia of Industrial Chemistry, 5th Ed, Weinheim: Wiley-VCH Press, 1985, 269.

[3] A. Sakthivel, P. Selvam, J. Catal., 2002, 211, 134.

[4] J L. Tao, D. J. Tang, Q. Li, Z. L. Yu, E. Z. Min, J. Nat. Gas. Chem., 2001, 


\title{
Graphical Abstract
}

Chin. J. Catal., 2016, 37: 273-280 doi: 10.1016/S1872-2067(15)61014-2

The synthesis of Co-doped SAPO-5 molecular sieve and its performance in the oxidation of cyclohexane with molecular oxygen

Zhun Xiao, Wangcheng Zhan *, Yun Guo, Yanglong Guo, Xueqing Gong, Guanzhong Lu*

East China University of Science and Technology

Cobalt-doped SAPO-5 molecular sieves showed a high activity for the oxidation of cyclohexane with $\mathrm{O}_{2}$. The catalyst behaved with good stability for this reaction.

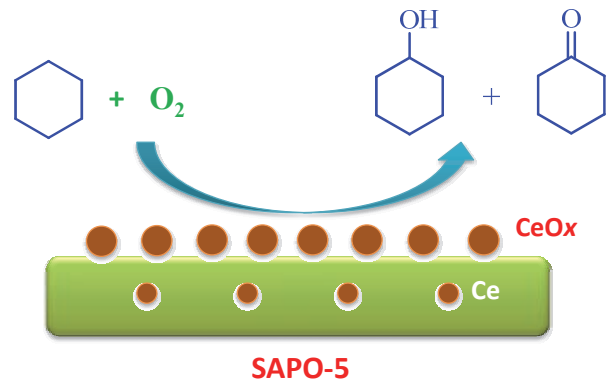

10, 295.

[5] R. J. Wicker, Chem. Ind., 1967, (11), 431.

[6] U. Schuchardt, D. Cardoso, R. Sercheli, R. Pereira, R. S. da Cruz, M. C. Guerreiro, D. Mandelli, E. V. Spinace, E. L. Fires, Appl. Catal. A, 2001, 211, 1 .

[7] I. Hermans, P. Jacobs, J. Peeters, Chem. Eur. J., 2007, 13, 754.

[8] Y. C. Zhang, W. L. Dai, G. J. Wu, N. J. Guan, L. D. Li, Chin. J. Catal., 2014, 35: 279.

[9] D. Verboekend, M. Milina, J. Perez-Ramirez, Chem. Mater., 2014, 26: 4552 .

[10] R. W. Dorner, N. J. Begue, D. Y. Petrovykh, D. R. Hardy, F. W. Williams, G. W. Mushrush, H. D. Willauer, Petrol. Sci. Technol., 2014, 32: 1375 .

[11] S. Maurelli, G. Berlier, M. Chiesa, F. Musso, F. Cora, J. Phys. Chem. C, 2014, 118, 19879.

[12] S. Devika, B. Sundaravel, M. Palanichamy, V. Murugesan, J. Nanosci. Nanotechnol., 2014, 14, 3187.

[13] E. Gianotti, M. Manzoli, M. E. Potter, V. N. Shetti, D. Sun, J. Paterson, T. M. Mezza, A. Levy, R. Raja, Chem. Sci., 2014, 5, 1810.

[14] M. E. Potter, M. E. Cholerton, J. Kezina, R. Bounds, M. Carravetta, M. Manzoli, E. Gianotti, M. Lefenfeld, R. Raja, ACS Catal., 2014, 4, 4161.

[15] A. K. Singh, R. Yadav, V. Sudarsan, K. Kishore, S. Upadhyayula, A. Sakthivel, RSC Adv., 2014, 4, 8727.

[16] J. R. Chen, J. Z. Li, C. Y. Yuan, S. T. Xu, Y. X. Wei, Q. Y. Wang, Y. Zhou, J. B. Wang, M. Z. Zhang, Y. L. He, S. L. Xu, Z. M. Liu, Catal. Sci. Technol., 2014, 4, 3268.
[17] J. W. Liu, Z. F. Liu, G. Feng, D. J. Kong, J. Phys. Chem. C, 2014, 118, 18496.

[18] X. L. Wei, X. H. Lu, T. J. Zhang, X. Chu, D. Zhou, R. F. Nie, Q. H. Xia, Microporous Mesoporous Mater., 2015, 214, 80.

[19] L. J. Wang, C. W. Guo, S. R. Yan, X. D. Huang, Q. Z. Li, Microporous Mesoporous Mater., 2003, 64, 63.

[20] S. Lim, D. Ciuparu, C. Pak, F. Dobek, Y. Chen, D. Harding, L. Pfefferle, G. Haller, J. Phys. Chem. B, 2003, 107, 11048.

[21] A. P. Katsoulidisa, D. E. Petrakisa, G. S. Armatasa, P. N. Trikalitisc, P. J. Pomonis, Microporous Mesoporous Mater., 2006, 92, 71.

[22] Q. Zhao, X. P. Zhou, M. R. Ji, H. H. Ding, T. S. Jiang, C. S. Li, H. B. Yin, Appl. Surf. Sci., 2011, 257, 2436.

[23] A. Szegedi, M. Popova, C. Minchev, J. Mater. Sci., 2009, 44, 6710.

[24] M. Akcay, Appl. Catal. A, 2005, 294, 156.

[25] C. A. Tolman, J. D. Druliner, M. J. Nappa, N. Herron, in: C. L. Hill Ed, Activation and Functionalization of Alkanes, New York, Wiley-Interscience, 1989, 316.

[26] M. Conte, X. Liu, D. M. Murphy, K. Whiston, G. J. Hutchings, Phys. Chem. Chem. Phys., 2012, 14, 16279.

[27] I. Hermans, T. L. Nguyen, P. A. Jacobs, J. Peeters, ChemPhysChem, 2005, 6, 637.

[28] R. P. Houghton, C. R. Rice, Polyhedron, 1996, 15, 1893.

[29] D. L. Vanoppen, D. E. De Vos, M. J. Genet, P. G. Rouxhet, P. A. Jacobs, Angew. Chem. Int. Ed., 1995, 34, 560.

[30] X. Liu, Y. Ryabenkovs, M. Conte, Phys. Chem. Chem. Phys., 2015, 17, 715.

[31] B. P. C. Hereijgers, B. M. Weckhuysen, J. Catal., 2010, 270, 16.

\section{Co掺杂SAPO-5分子篮制备及其催化氧气氧化环己烷反应性能}

\author{
校 准, 詹望成, 郭耘, 郭杨龙, 龚学庆, 卢冠忠 ${ }^{*}$ \\ 华东理工大学结构可控先进功能材料及其制备教育部重点实验室和工业催化研究所，上海200237
}

摘要: 环己醇和环己酮(KA油)是制备尼龙所需材料己二酸和己内酰胺的重要中间体, 也可用作油漆、农药和染料等的溶剂以及染 色和褪光丝的均化剂等. 工业上制取KA油的方法主要为苯酚加氢法、环己烯水合法和环已烷氧化法, 其中环己烷氧化法最为普 遍, 是非常重要的工业过程. 为获得适宜的KA油选择性, 工业上普遍采用Co盐为催化剂, 将环已烷氧化单程转化率控制在 $5.0 \%$ 以 下, 从而使得产物选择性达到 $70 \%$ 以上. 该环已烷氧化制KA油过程不仅生产效率较低, 而且所用均相催化剂因分离困难而不能重 复使用. 因此, 当前关于环己烷氧化反应催化剂的研究均是围绕多相催化剂进行.

氧气选择性氧化环己烷反应因具有更高的原子经济性而逐渐成为环己烷氧化法制KA油研究中最具挑战性的课题. 该反应是 自由基机理, 而 $\mathrm{Co}^{2+}, \mathrm{Cr}^{3+}, \mathrm{Mn}^{2+}$ 和 $\mathrm{Ce}^{2+}$ 等金属离子可以促进自由基链反应, 因此含有这些金属的多相催化剂被广泛用于该反应. 另一方面, AlPO- $n$ 系列分子篮由于具有特殊的孔结构和一定的表面酸性, 在催化反应中显示出较大的应用潜力. 如果进行杂原子 掺杂, 通过改变分子篮骨架的电荷平衡, 可以有效提高其表面酸性. 例如磷酸硅铝分子篮(SAPO-5)具有中等强度的酸性和良好的 择形性, 因而作为固体酸催化剂广泛用于乙醇脱水、甲醇制烯烃、丙烯聚合和苯乙烯环氧化等反应, 表现出较高的选择性和良好 
的稳定性.

本文以传统均相Co盐催化剂的多相化为出发点, 制备了Co掺杂SAPO-5与分子篮催化剂(Co-SAPO-5), 考察了Co掺杂量对催 化剂结构、表面性质以及氧气选择性氧化环已烷反应性能的影响. 结果表明, 一部分Co进入分子篮骨架, 同时有少量Co以氧化钴 形式高度分散在SAPO-5表面. Co掺杂对SAOP-5催化剂比表面积没有显著影响, 但可使其孔体积减小. 相反, Co掺杂可以提高 SAOP-5 分子篮表面B酸性位数量和总酸量. 活性测试结果表明, 环己烷转化率随着Co-SAPO-5催化剂中Co含量的增加而增加, 但 KA油选择性在转化率高于 $6.3 \%$ 时急剧下降. 还考察了反应温度、反应时间、初始氧气压力和催化剂用量对Co-SAPO-5分子篮催 化剂性能的影响, 得到了最优反应条件. 以Co-SAPO-5-0.2 (Co/Si摩尔比为 0.2$)$ 分子篎为催化剂时, KA油总收率最高可达 $7.8 \%$. 另 外, Co-SAPO-5催化剂在环己烷氧化反应中显示出很好的稳定性, Co-SAPO-5-0.2催化剂套用6次后活性几乎没有变化.

关键词: SAPO-5分子篮; 钴; 环已烷; 选择氧化; 氧气

收稿日期: 2015-08-25. 接受日期: 2015-11-10. 出版日期: 2016-02-05.

*通讯联系人. 电话/传真: (021)64252923; 电子信箱: zhanwc@ecust.edu.cn

\#通讯联系人. 传真: (021)64252827; 电子信箱: gzhlu@ecust.edu.cn

基金来源：国家重点基础研究发展计划(2010CB732300)；国家自然科学基金(21103048).

本文的英文电子版由Elsevier出版社在ScienceDirect上出版(http://www.sciencedirect.com/science/journal/18722067). 